\title{
Index of Volume 18 (2000)
}

\section{Number 1}

\section{A. Cohen, H. B. Sackrowitz}

Testing whether treatment is „better" than control with ordered categorical data:

Definitions and complete class theorems $\ldots \ldots \ldots \ldots \ldots \ldots \ldots \ldots \ldots \ldots \ldots \ldots \ldots$

T. Kusama, N. Koyama

Complete classes in comparison of sequential binomial experiments

$Q . Y u$

Inadmissibility and admissibility of randomized Wilcoxon tests in discrete

two-sample problems

\section{A. Janssen}

Nonparametric bioequivalence tests for statistical functionals and their

efficient power functions

A.-E.S Abd-Rabou, E.-E.A.A. Aly

Weighted tests for a change in the regression slope $\ldots \ldots \ldots \ldots \ldots \ldots \ldots \ldots \ldots$

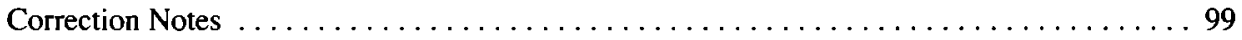

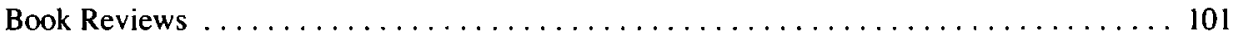

\section{Number 2}

E. Grycko, O. Moeschlin

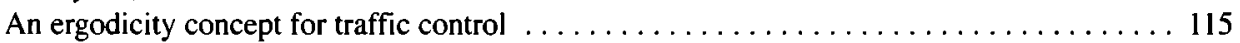

E. Marchand, B. MacGibbon

Minimax estimation of a constrained binomial proportion $\ldots \ldots \ldots \ldots \ldots \ldots \ldots \ldots$

G. Iliopoulos, S. Kourouklis

Interval estimation for the ratio of scale parameters and for ordered scale parameters 
N. Pal, Wooi K. Lim

Estimation of a correlation coefficient: Some second order decision-theoretic results

H. P. Singh, M. Ruiz Espejo

An improved class of chain regression estimators in two phase sampling

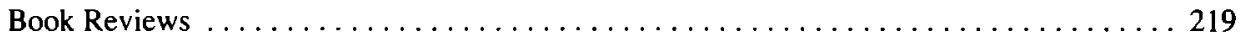

\section{Number 3}

P. Lachout, V. Paulauskas

On the second-order asymptotic distribution of M-estimators

D. Fourdrinier, A.-S. Lemaire

Estimation of the mean of a $l_{1}$-exponential multivariate distribution

C. El-Nouty, A. Guillou

On the bootstrap accuracy of the Pareto index

A. van Aubel, W. Gawronski

Asymptotics and bounds for the modes of noncentral distributions

E. Cramer

Probability measures with given marginals and conditionals: $I$-projections and conditional iterative proportional fitting

Book Reviews 


\section{Number 4}

\section{B. Rémillard, R. Theodorescu}

Inference based on the empirical probability generating function for mixtures

of Poisson distributions.

M. Baron

On statistical inference under asymmetric loss functions

D. Louani

Exact Bahadur efficiencies for two-sample statistics in functional density estimation

\section{J. Leclerc}

Strong limiting behavior of two estimates of the mode:

the shorth and the naive estimator

K.D. Schmidt

Statistical decision problems and linear prediction under vague prior information

Book Reviews 
